\title{
REAPPRAISAL OF G1-PHASE ARREST AND SYNCHRONIZATION BY LOVASTATIN
}

\author{
STEPHEN COOPER
}

\begin{abstract}
Department of Microbiology and Immunology, University of Michigan Medical School, Ann Arbor, MI 48109-0620, U.S.A.
\end{abstract}

Received 8 January 2002; revised 25 April 2002; accepted 1 May 2002

\begin{abstract}
It has been proposed that lovastatin arrests cells in the G1-phase of the division cycle, and that release from lovastatin inhibition produces a synchronized culture. A new method of methocel time-lapse-videography has been used to analyse cell division patterns following lovastatin treatment. Release of L1210 cells from lovastatin inhibition failed to produce synchronized divisions. Moreover, contrary to earlier proposals, lovastatin did not arrest cells with a G1-phase amount of DNA. Analysis of previous reports of 'synchronization' and growth-arrest support these findings. It is concluded that lovastatin neither synchronizes cells, nor arrests cells in the G1-phase of the division cycle.

(C) 2002 Elsevier Science Ltd. All rights reserved.
\end{abstract}

KEYWORDS: cell cycle; time-lapse videography; methocel.

\section{INTRODUCTION}

A synchronized culture is one in which cells of similar age progress as a cohort through the division cycle. Ideally, in an unperturbed synchronized cell culture, specific events occurring during the normal mammalian division cycle could be accurately determined.

Crude or harsh synchronization methods can lead to artifacts that vitiate attempts to understand the 'normal' cell cycle (Abbo and Pardee, 1960), where 'normal' refers to cells growing in exponential culture without perturbations due to starvation or inhibition. It has been proposed that the inhibitor lovastatin can arrest cells in the G1 phase of the division cycle and that a synchronized culture is produced upon release (Keyomarsi et al., 1991). The experiments presented here examine the effect of lovastatin on L1210 cells, with specific attention being paid to the proposal that lovastatin synchronizes cells. These experiments show that lovastatin inhibits cell growth, but that the cells are neither arrested at a point in G1 nor synchronized upon release.

*To whom correspondence should be addressed: Tel.: 734-764-4215; Fax: 734-764-3562; E-mail: cooper@umich.edu

$1065-6995 / 02 / \$$-see front matter

\section{MATERIALS AND METHODS}

\section{Cells and cell culture}

Murine L1210 lymphoma cells were grown at $37^{\circ} \mathrm{C}$ in Liebovitz's L15 medium with glutamine (Gibco, Rockville, MD, U.S.A.), 10\% fetal bovine serum (FBS, BioWhittaker, Walkersville, MD, U.S.A.), penicillin $(100 \mathrm{U} / \mathrm{ml})$, and streptomycin $(100 \mu \mathrm{g} /$ $\mathrm{ml}$ ). Liebovitz's L-15 medium is strongly buffered so that a $\mathrm{CO}_{2}$ atmosphere is not required for cell growth. Incubation was carried out in tightly capped T-25 or T-175 flasks (Corning, Inc., Corning, NY, U.S.A.).

\section{Cell cycle analysis by flow cytometry}

L1210 cells are non-adherent cells, and can be harvested directly by centrifugation at $\sim 800 \times \boldsymbol{g}$. Collected cells were suspended in $1 \mathrm{ml}$ phosphatebuffered saline (PBS) and an equal volume of ethanol was added with vortexing. For flow cytometric analysis, the collected cells were resuspended in a solution of $50 \mu \mathrm{g} / \mathrm{ml}$ propidium iodide and $100 \mu \mathrm{g} / \mathrm{ml}$ RNase in PBS. Flow cytometric analysis was performed with a Coulter Epics analyser, and the data analysed using the Multicycle program 
(Phoenix Flow Systems, San Diego CA, U.S.A.) to determine the relative fraction of cells with G1-, S-, and $\mathrm{G} 2 / \mathrm{M}$-amounts of DNA.

\section{Preparation of L-15/methylcellulose medium}

To prepare a $1 \%$ Methocel medium, $5.6 \mathrm{~g}$ of Methocel (hydroxypropyl methylcellulose; Dow Chemical Corporation, Midland, MI, U.S.A.) was added to a 21 flask containing a magnetic stirrer. The dry methocel was sterilized in an autoclave. After cooling, $560 \mathrm{ml}$ of complete growth medium (L-15 with FBS, penicillin and streptomycin) was added. Some experiments have used an addition of $20 \mu \mathrm{g} / \mathrm{ml}$ fungizone (Gibco, Rockville, MD, U.S.A.) to reduce growth of molds that may have contaminated the non-autoclavable temperature probe. Other methocel concentrations (up to $2 \%$ methocel allows satisfactory cell growth) can be prepared accordingly. The flask is placed on a magnetic stirrer and the methocel is dissolved with slow stirring in a cold room for $48-72 \mathrm{~h}$. The methocel-medium is then centrifuged at $1900 \times g$ for $30 \mathrm{~min}$ to remove particulate matter present in the methocel that would interfere with videomicroscopy. The clarified methocel medium is distributed in $20-30 \mathrm{ml}$ volumes to $\mathrm{T}-25$ flasks and stored in the cold.

\section{Videographic analysis of cells in methocel medium}

L-1210 cells $\left(2-3 \times 10^{6}\right.$ cells optimally) were added to the clarified methocel medium in a T-25 flask. In a typical experiment, $10-15 \mathrm{ml}$ cells at $2 \times 10^{5} / \mathrm{ml}$ were spun at $800 \times \boldsymbol{g}$ for $2 \mathrm{~min}$, and then resuspended in the small residual volume of medium $(0.1-0.3 \mathrm{ml})$. The cells were then added to a $\mathrm{T}-25$ flask with methocel medium. If the original cell concentration was high enough, cells (in $1 \mathrm{ml}$ medium) were added without the initial centrifugation. The cells were distributed throughout the medium by gentle turning and rocking of the flask. The flask was then placed in a swinging bucket rotor and centrifuged at $800 \times \boldsymbol{g}$ for $10-15 \mathrm{~min}$ to bring cells to the bottom of the flask (Fig. 1). This placed the cells in one focal plane so that time-lapse video recording could be undertaken; the filming set-up is illustrated in Figure 1. When cells inhibited by lovastatin were analysed, an additional wash step with complete medium was included to remove residual lovastatin.

The temperature in the flask was controlled with a calibrated electronic digital thermometer (Control Company, 308 West Edgewood,

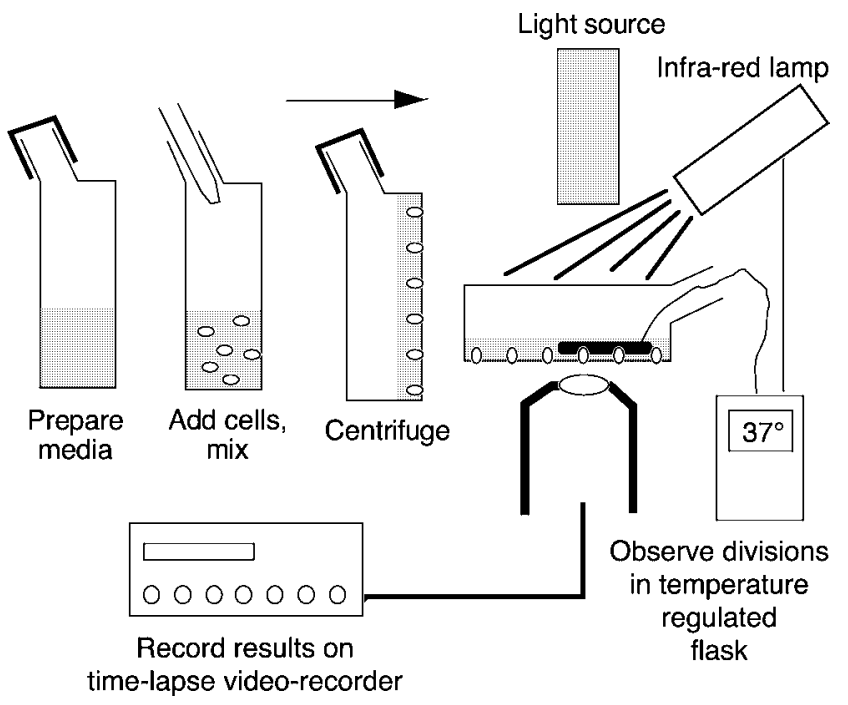

Fig. 1. Description of the Methocel-videography (MCV) method. A small flask $\left(25 \mathrm{~cm}^{2}\right)$ is prepared with approximately $25 \mathrm{ml}$ of methocel-L15 medium. Approximately $2-3 \times 10^{6}$ cells are added to the flask and the cells are mixed throughout the medium. The flask is then centrifuged to place the cells against the bottom of the flask. A thermocouple is inserted into the flask. The thermocouple reads the temperature inside the flask and controls an infrared lamp that heats the medium by illumination. The cells in the flask are observed using an inverted microscope. A time-lapse video recorder collects the images.

Friendswood, TX 77546, U.S.A.; model NEW 11463-47A). The thermometer controls a heat lamp (an infrared lamp and a normal white floodlight have been used with equally good results) thus regulating the temperature of the growth medium. The brightness or intensity of the heat lamp is adjusted either by adjusting the distance of the lamp from the flask or by using a transformer to modulate the current to the lamp. A smooth cycling of the lamp ensures maintenance of the medium temperature with an oscillation of $1^{\circ} \mathrm{C}$. Because of the use of Liebovitz's L-15 medium, no $\mathrm{CO}_{2}$ gas is required during the filming.

Even if one wanted to use $\mathrm{CO}_{2}$ to buffer the medium, it is not clear that the cells at the bottom of the flask would be affected. The viscous methocel-containing medium does not allow normal convection currents to mix the growth medium. Therefore it is not clear that any gaseous phase can be used to affect cell growth at the bottom of the flask. An additional reason to not use $\mathrm{CO}_{2}$ is that the simple method described here does not require such a measure. The simplicity of the method, and the successful growth of cells without additional buffering (either in conventional liquid growth medium or in the methocel 


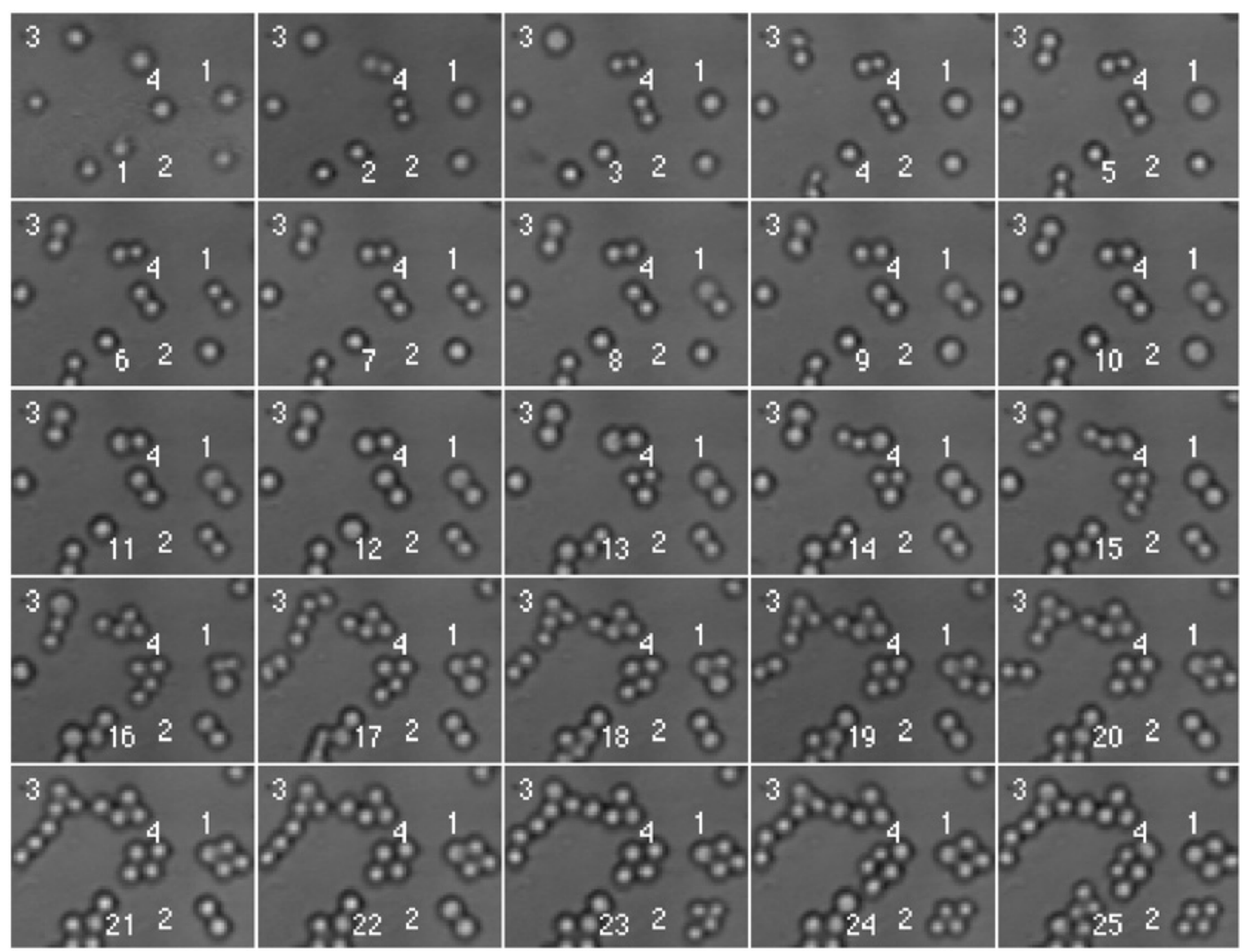

Fig. 2. Montage illustrating dividing cells. The panels are numbered 1-25 at the bottom. Four starting cells (1-4) are numbered. Cell ' 1 ' is noted to divide in panel 5 (by convention, the panel before a cell goes to two cells is called the panel of division), and the two daughter cells divide in Panel 15 and 18. Cell 2 (lower right) divides in panel 10, and the daughter cells are observed to both divide in panel 22. Cell 3 (upper left) divides in panel 3, and the daughter cells divide in panel 14 and 16 . Cell 4 divides in panel 1, and the daughter cells divide in panels 12 and 14. As the time between frames is $1 \mathrm{~h}$, the interdivision times for the two daughter cells can be summarized: cell 1,10 and $13 \mathrm{~h}$; cell 2, 12 and $12 \mathrm{~h}$; cell 3,11 and $13 \mathrm{~h}$, and cell 4,11 and $13 \mathrm{~h}$. The identifying numbers can be placed on all cells before the analysis to avoid missing any cells.

medium) indicates that one may abstain from using $\mathrm{CO}_{2}$.

Microscopy was carried out with inverted microscopes fitted with MTI cathode ray TV cameras that pass the image to Panasonic VCR recorders. By setting the capture time at $480 \mathrm{~h}$, a 240 -fold reduction in recording time was obtained. Thus, a $24 \mathrm{~h}$ period of cell growth is recorded in $6 \mathrm{~min}$ at normal $2 \mathrm{~h}$ tape-speed.

A consideration regarding videomicroscopic analysis of cells is the continuous use of microscope illumination, which could affect cell growth. It is generally accepted that the less light, the better. In practice, the amount of microscope light was kept low and clearly less than ambient room light. More importantly, three experiments showed that continuous illumination of the cells by the microscope light (or the additional light from the heating lamps) is not a problem. First, no difference in growth pattern was observed between cells illuminated by the microscope light and cells outside the range of the illuminating light. Second, control flasks identical to flasks being taped but placed in a $37^{\circ} \mathrm{C}$ incubator have a growth pattern similar to that in the experimental flask. Third, the cellular interdivision times do not increase as they occur later in the experimental incubation period. Absence of an increase in interdivision times indicated no significant perturbation due to illumination.

The temperature measured by the thermometer probe may have been slightly different from the temperature of the cells touching a plastic surface. The temperature used in these experiments was empirically tested by comparing cell growth in a flask incubated in a $37^{\circ} \mathrm{C}$ incubator with a flask on the microscope stage. A set-point of $38^{\circ} \mathrm{C}$ appeared optimal.

An example of the patterns of cell division obtained by time-lapse is shown in Figure 2, each 
panel being $1 \mathrm{~h}$ apart; hence the number of panels between divisions gives the interdivision time for a given cell to the nearest hour.

\section{Lovastatin inhibition of L1210 cells}

Lovastatin (from Merck (Whitehouse Station, NJ, U.S.A.) and Wako, (Osaka, Japan)) was dissolved in ethanol at a stock concentration of $32 \mathrm{mM}$. Control experiments showed that the residual ethanol added to the cells on dilution of the stock did not affect growth.

\section{Analysis using NIH image}

Images from the videotape were captured at fixed intervals by the NIH image program (http:// rsb.info.nih.gov/nih-image) using the 'make movie' mode, as the film played at normal speed. Images were generally captured every $15 \mathrm{~s}$ of tape time or every hour of cell growth time. Thus, capturing 49 frames would cover two complete days of cell growth. Since the interdivision time of L1210 cells is $12 \mathrm{~h}$, at least two cell divisions could be easily observed.

Before image analysis, all cells were numbered to ensure that all were accounted for. After image capture, the status of the cells was determined by running through the frames and flipping rapidly between two images, from which it was simple to determine the time of cell division. The number of images between cell divisions determined the interdivision time.

\section{Analysis of division patterns}

A graphical approach to analysing the division patterns determined whether cells were synchronized. Thus, rather than using statistical analysis, the general distribution of interdivision times following an attempted synchronization was obtained, from which one can see whether or not cells were synchronized (Fig. 3), even by following relatively few cells. A narrowing of the time band within which divisions occurred is indicative of the degree of synchronization.

Graphical analysis was supplemented by a simple statistical analysis of the numerical data by measuring the coefficient of variation $(\mathrm{CV})$ of the initial times until first division. A group of cells all of different ages (from newborn until just about to divide) gives the maximal range of division times, while synchronized cultures would produce a narrower distribution.

\section{RESULTS}

\section{Cell division in methocel medium}

The division pattern of untreated, control cells are illustrated in Figure 2. By convention, the frame before a division is taken as the time of cell division of a cell. If the time between frames is $1 \mathrm{~h}$ (Fig. 2), calculating the time until the first, second, and third divisions (the $\mathrm{A}, \mathrm{B}$, and $\mathrm{C}$ divisions in Fig. 3 ) is done by counting the frames between divisions.

\section{Exponential growth analysed in methocel medium}

An example of the pattern of cell division obtained for unperturbed, exponentially growing cells is presented in Figure 4(a). The observed pattern fits well with the expected theoretical curve (see Fig. $3(\mathrm{~d}, \mathrm{i}))$. The $\mathrm{CV}$ of the first division time (division A defined in Fig. 3(a)) is 0.57 . The average interdivision times for the second and third divisions is $13.7 \mathrm{~h}$, which correlates well with the doubling time of the L1210 cells observed in exponential growth in suspension culture. The absence of an upward slope for the second and third divisions indicates that there is no long-term effect of continuous illumination or growth in methocel.

\section{Analysis of lovastatin inhibited cells using methocel medium}

Lovastatin inhibition of L1210 cell growth is complex and dependent on both concentration and the time of treatment. Above $80 \mu \mathrm{M}$ lovastatin, or treatment for more than $48 \mathrm{~h}$, a substantial amount of cell killing occurs, i.e. many cells were unable to divide during a further $48 \mathrm{~h}$ incubation after removing the lovastatin. At $20-40 \mu \mathrm{M}$ lovastatin, cell killing was not significant, although cell number failed to increase during lovastatin treatment. A series of experiments showed no indication of synchronization as determined by time-lapse studies. A variety of treatment times and lovastatin concentrations were studied in order to find some indication of synchronization but all experiments were negative.

A typical lovastatin inhibition/release experiment is presented in Fig. 4(b). The pattern observed for the first, second, and third divisions (see Fig. 3(a)) do not suggest any apparent synchronization. The $\mathrm{CV}$ of the first division (division $\mathrm{A}$ ) is 0.56 ; this $\mathrm{CV}$ 
(a)

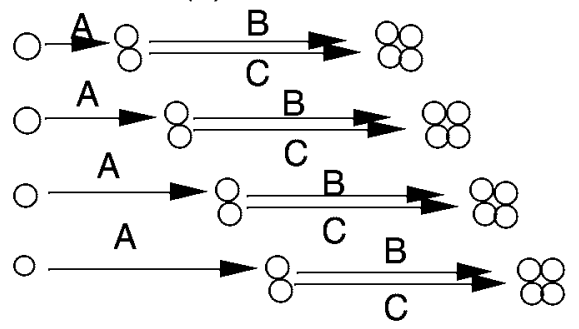

(b)

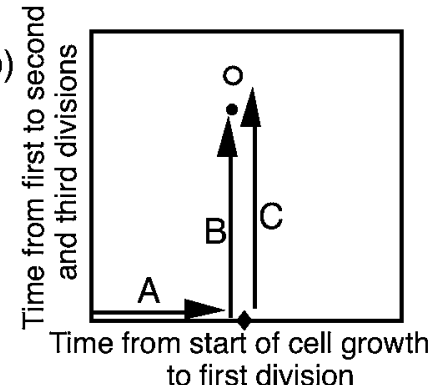

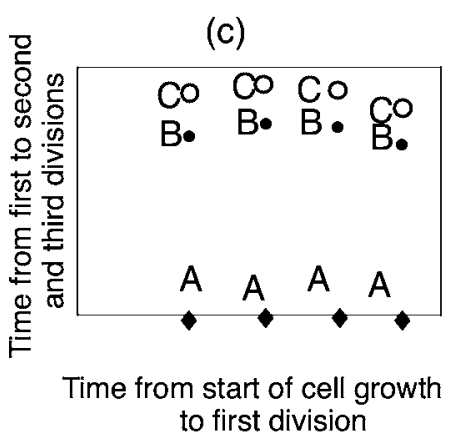
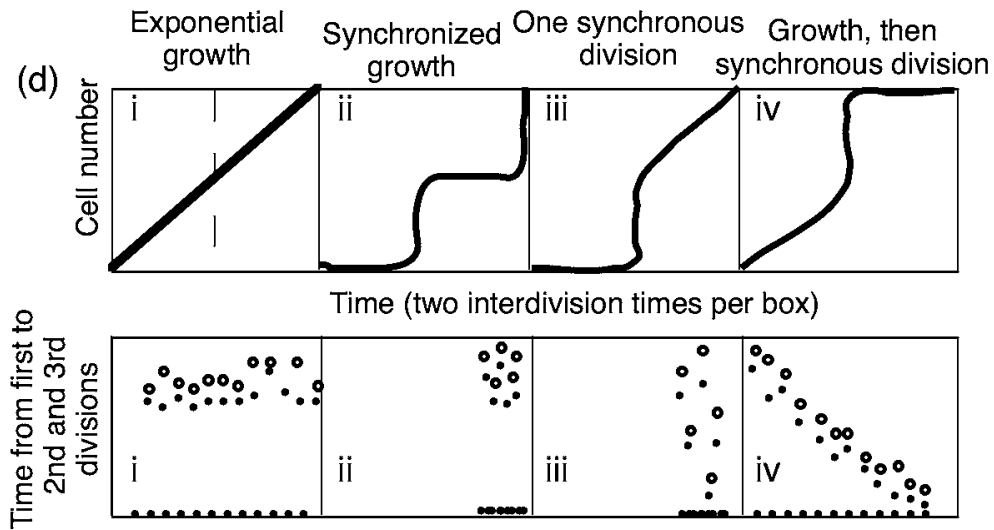

Time until first division

Fig. 3. Methocel Videographic (MCV) Analysis of the Cell Cycle. Panel (a) shows the terminology for the first division of cells (in an exponential culture) and the two subsequent divisions. The first division is observed to occur over a variation in times because the initial cells from an exponential culture are cells of all different ages. The durations of the intervals until the second and third cell divisions are less variable. These times are equal to the normal interdivision time of exponentially growing cells. Panel (b) shows a plotting of times a, b, and c (from panel a) for an exponential culture. Since the initial cells are of variable ages the initial cell division is very varied in time, while the second and third divisions are expected to be constant for all cell groups. Panel (c) is an illustration of the expected plot for all four cells in panel (a). Thus each cell divides 'A' minutes after the start of the experiment yielding a point at the bottom of the graph, and then the ' $\mathrm{B}$ ' and ' $\mathrm{C}$ ' times associated with that particular point are plotted above the respective 'A' point. In panel (d) are four examples of what might be expected for possible results after cells that are untreated or synchronized are analysed. In (d,i) an exponential pattern of growth (upper panel) and its expected plotting according to panel (b) are shown. In (d,ii) the expectation for the growth (upper figure) of a synchronized culture and its expected plotted results (lower figure) are shown. Two other examples show hypothetical patterns where an initial synchronous division is followed by normal growth (d,iii) and a pattern where exponential growth is followed by a single synchronous division (d,iv).

does not suggest any narrowing of the interdivision times of the first division. The average interdivision time for the second and third divisions is 15.9 h, slightly longer than the control in Fig. 4(a). This slight lengthening of interdivision time after removal of lovastatin should also be taken as an indication that the cells produced after release of inhibition may be perturbed.

To summarize a number of experiments, no narrowing of the time of the first division occurred, and no pattern similar to that in Figure 3(d,ii) was ever observed. The relevance of this result to cells in general will be considered in the Discussion.

\section{DNA pattern of cells arrested by lovastatin}

L1210 cells were incubated in a number of experiments for various lengths of time with different concentrations of lovastatin, and the final cellcycle-phase-distribution was determined by flow cytometry. Three different and representative experiments are presented in Figure 5, showing that it is difficult, and perhaps not possible, to get $100 \%$ of the cells with a G1-phase amount of DNA. As shown in Figure 5, there is only some small augmentation of the fraction of cells with a G1-phase amount of DNA.

\section{DISCUSSION}

\section{Definitions of synchronization and G1-phase arrest}

While the definition of a synchronized culture may be widely accepted in theory, in practice the definition of a synchronized culture is more elusive. Here 

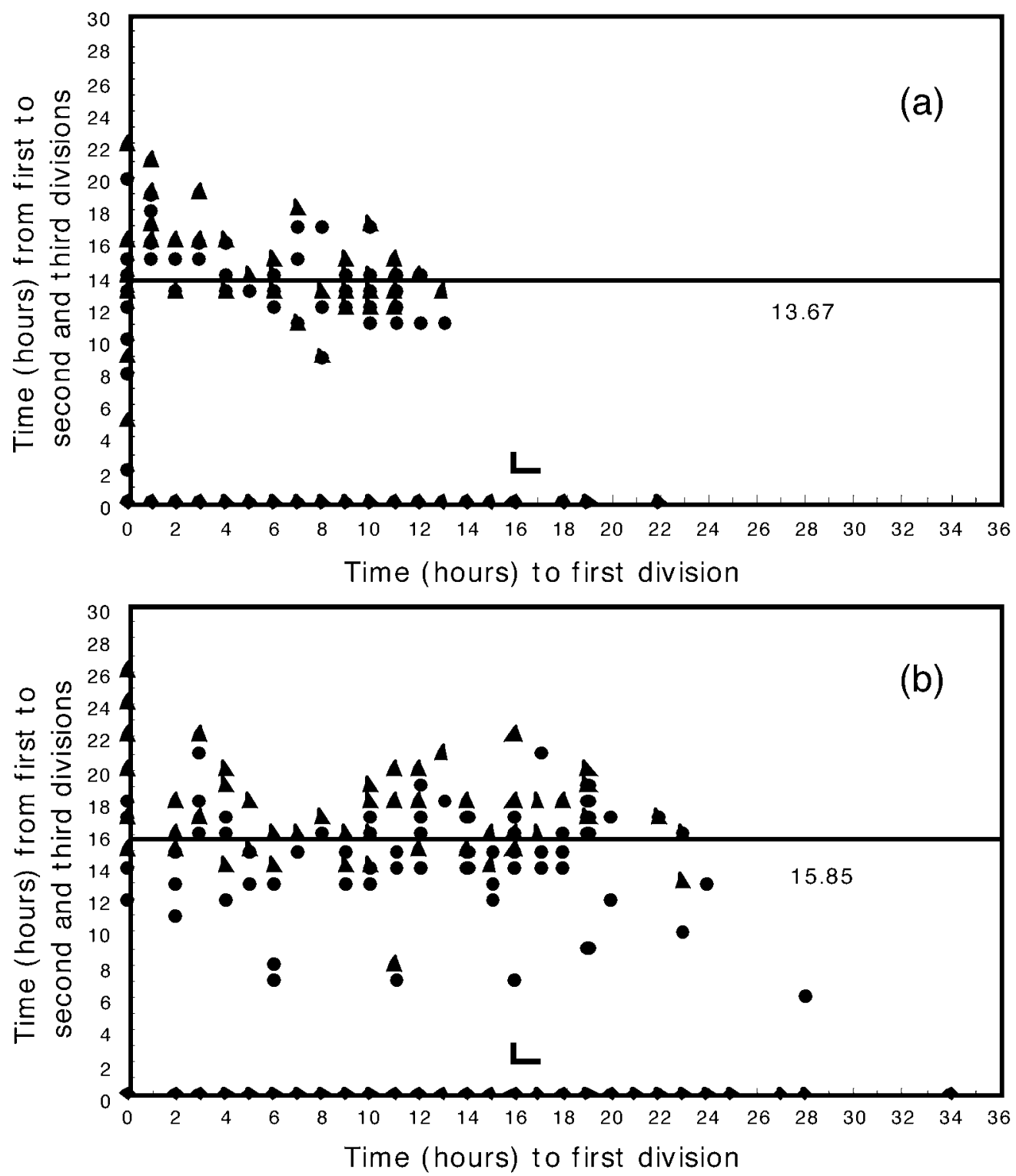

Fig. 4. Division patterns for control and lovastatin inhibited cells. (a) Exponential culture analysed by videography. Cells were analysed by plotting the data as described in Figure 3. The diamond point $(\bullet)$ is the time for the initial division; the filled circle (O) and the filled triangle $(\boldsymbol{\Delta})$ are the second and third divisions respectively, corresponding to the daughter cells on the $\mathrm{x}$-axis. The average interdivision time for the second and third divisions is 13.67. The ' $L$ ' shaped figure at the bottom is an indication of what a $1 \mathrm{~h}$ time interval is in the horizontal and vertical dimensions; this is the error that can be placed on all points due to the use of images of dividing cells separated by $1 \mathrm{~h}$. The coefficient of variation of the first divisions is 0.57 . (b) Lovastatin released cells. Cells were incubated with $20 \mu \mathrm{M}$ lovastatin for $20 \mathrm{~h}$, washed with fresh medium, and analysed by the methocel-time-lapse videography method. Symbols are as in panel (a). The second and third divisions are somewhat longer than the control $(15.85 \mathrm{~h})$, but there is no indication of any pattern reflecting synchronization. Furthermore, the CV of the first division time is 0.56, supporting the proposal that there is no indication of a narrowing of the interdivision times for the first division following release from lovastatin treatment. In panels (a) and (b) not all points are shown as some points fall on the same location in the graph, and sometimes a third division is not observed before the termination of taping.

it is proposed that one of the fundamental properties a synchronized culture must have is that the culture shows synchronized divisions. If a culture does not exhibit synchronized divisions, then it is not possible to know at any point during growth where the cells are during the division cycle. For example, if one started out with newborn cells that had a mixture of 10,20 , and $40 \mathrm{~h}$ times until their first division, after $10 \mathrm{~h}$ of growth some cells would be at the end of the cycle, some cells at the middle of the cycle, and some cells at the beginning of the cycle. The cells would not be representative of any 

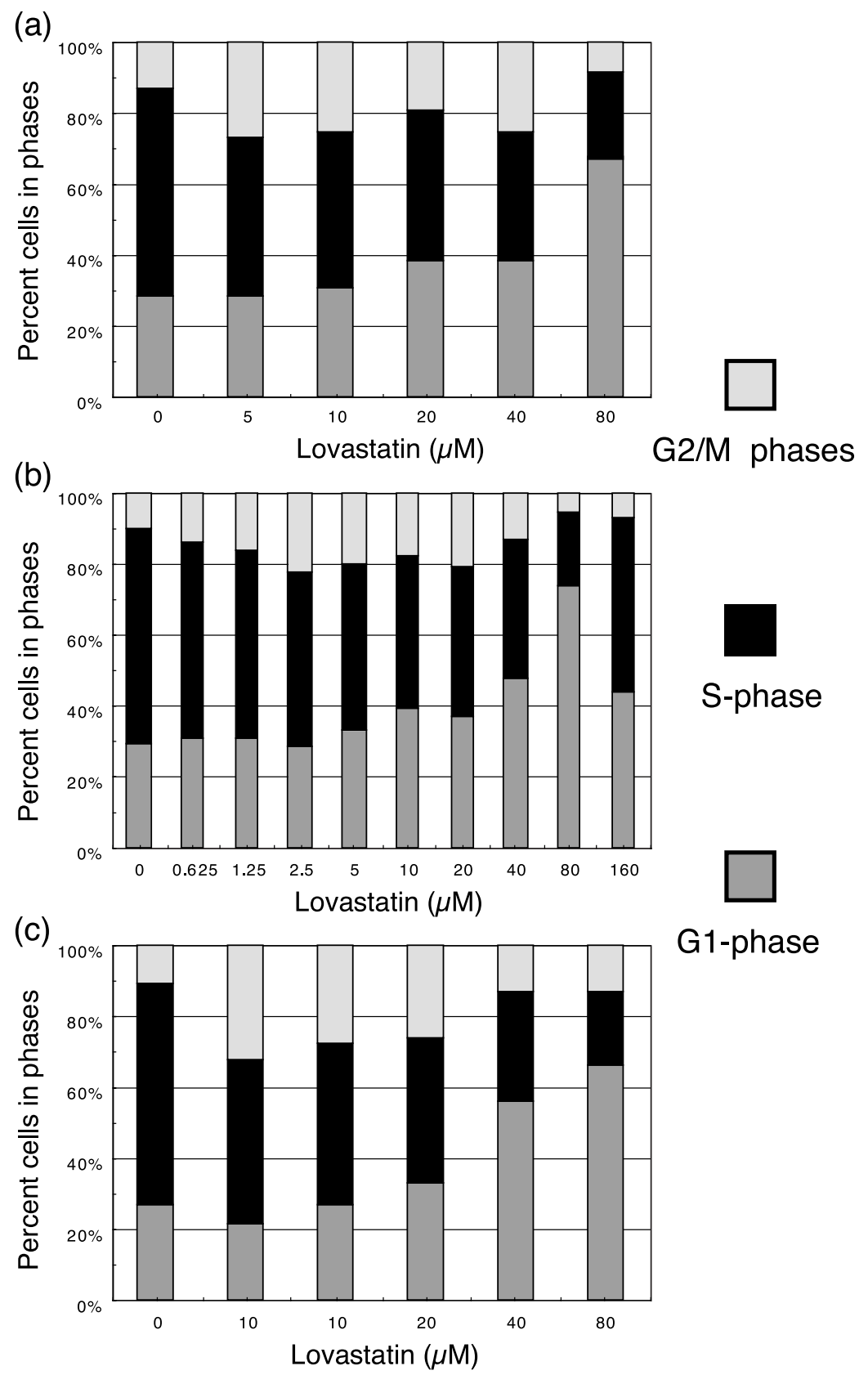

G1-phase

Fig. 5. Effect of lovastatin on DNA distributions. Three experiments are depicted (of numerous experiments with similar results). In each one, exponentially growing cells were placed with the indicated concentrations of lovastatin for (a) $24 \mathrm{~h}$, (b) $24 \mathrm{~h}$, and (c) $20 \mathrm{~h}$; at the end of the treatment the cells were analysed for DNA contents by flow cytometry as indicated in the methods. Note that there are indications in these experiments that the G1-phase (as a percent of total cells) increases, but at no time is there a pattern of cells all with a G1-phase amount of DNA.

particular phase or time during the division cycle. If the interdivision times are approximately the same for all cells, then one can assume that the cells can move as a uniform, narrow-aged cohort, through the phases of the division cycle.

There are presumably two reasons why cell numbers are usually not determined for synchronization experiments. First, to study two cycles of a culture that grows with a $24 \mathrm{~h}$ doubling time, samples for cell number determination would have to be taken over relatively short intervals $(\sim 2 \mathrm{~h})$ for $\sim 48 \mathrm{~h}$; this is labor intensive. Second, since cell numbers will vary over a single interdivision time by a factor of 2 , highly reproducible cell counts are required to demonstrate synchronization. This is more difficult with commonly used adherent cell 
lines, due to sizeable variations in cell recovery. For these reasons, and not surprisingly, cell counts are presented in very few studies of synchronized cells.

In the absence of cell numbers, the primary approach to proposing or demonstrating that a culture is 'synchronized' is to assume that arrest of cells with similar DNA contents indicates synchronization. For example, inhibition or starvation of cells to produce cells with a G1-phase amount of DNA is assumed to produce a synchronized culture.

There is a lack of rigor and precision in defining a culture as arrested with a G1-phase amount of DNA. A rigorous definition of 'arrest with a G1phase amount of DNA' is that $100 \%$ of the cells have a G1-phase amount of DNA. A more difficult question is how to describe cells where there is less uniformity of DNA content following inhibition. For example, if only $95 \%$ of the cells have a G1-phase amount of DNA, should this be considered 'G1-phase arrest'? Perhaps this result should be more correctly described as 'arrest with $95 \%$ of the cells having a G1-phase amount of DNA'. With lower percentages of cells with a G1-phase DNA content, defining the cells as 'arrested in G1-phase' is even more difficult. At what point is the percentage enrichment of the G1 population not clearly and significantly different from an asynchronous population? It is proposed here that an accurate quantitative estimate of the fractions of cells exhibiting $2 \mathrm{C}, 4 \mathrm{C}$, and intermediate DNA contents should be reported. Thus, if cells have $80 \%$ G1phase DNA, $10 \%$ S-phase DNA, and 10\% G2/Mphase DNA, these cells should be described as having G1-, S-, and G2/M-phase DNA contents in the proportions 80:10:10. The interpretation of the actual results should then be distinct from the observed values. This is important because a biochemical event assigned to the G1 phase could at least be qualified or even challenged on the basis of the degree of arrest with a particular DNA content. A particular biochemical result attributed to G1 phase could still be attributed to the subordinate, contaminating fractions, such as $\mathrm{S}$ or $\mathrm{G} 2 / \mathrm{M}$, rather than assuming it relates to the G1 phase fraction.

There is another important critique of experiments demonstrating an increase in the fraction of cells with a G1-phase amount of DNA following addition of an inhibitor. If cell growth is slowed down but not actually arrested, and assuming S, $\mathrm{G} 2$ and $\mathrm{M}$ phases are the least invariant in traverse times, the bulk of the increase in interdivision time will be in G1 phase. This will lead to an increased fraction of cells with a G1-phase amount of DNA that is not due to 'arrest in G1 phase' (Cooper,
1979, 1998a,b, 2000). Thus, an increase in cells with a G1-phase amount of DNA may not be an indication of any synchronization of cells, much less arrest of cell growth.

\section{Previously published experimental determinations of 'Gl-phase arrest' with lovastatin}

The results in Figure 5 indicated that it is possible to inhibit cells with lovastatin, and yet not achieve $100 \%$ G1-phase DNA contents. Even an 80\% cellular accumulation of G1-phase DNA contents is difficult to attain. Since the phenomenon described as G1-phase arrest is ubiquitous in the literature, a failure on the part of the methods used here to obtain G1-phase arrested cells may be due to problems with the methods or cell strains used here, or a failure due to other unknown conditions. However, an objective analysis of previously published studies on lovastatin indicates that - despite claims of G1-phase arrest - the published results do not present a clear case for this observation. Indeed, most studies reveal an inability to produce a cell population truly arrested with a 'pure' G1phase amount of DNA.

For example, published results originally presented in a tabular form by Rao et al. (1999) have been replotted in Figure 6(a). These results were described as follows:

Treatment of cells with the pro-drug [ $\beta$-lactone] form of lovastatin resulted in inhibition of cell proliferation and pronounced CKI [cyclindependent-kinase inhibitor] induction in a dosedependent manner. The flow cytometric data shows that after treatment of cells with only $5 \mu \mathrm{M}$ pro-drug, the cells accumulate in the G1 phase with a concomitant reduction in $\mathrm{S}$ phase. [Italics added for emphasis.]

The results in Figure 6(a) demonstrate that there is no clear G1-phase arrest by any objective criteria. It is not obvious that the increase in cells with a G1-phase amount of DNA is greater than expected by experimental variation. Another table in the same paper showed an increase from 56\% G1-phase DNA content cells in the untreated control to $61-62 \%$ having a G1-phase amount of DNA after $40 \mu \mathrm{M}$ of either pro-lovastatin or lovastatin. This result is also described as a G1-phase arrest, but one cannot be other than highly skeptical of this conclusion.

Another experiment on lovastatin inhibition has been presented for a time course of lovastatin treatment. These results (replotted in Fig. 6(b)) are described (Rao et al., 1998) as follows: 
(a)

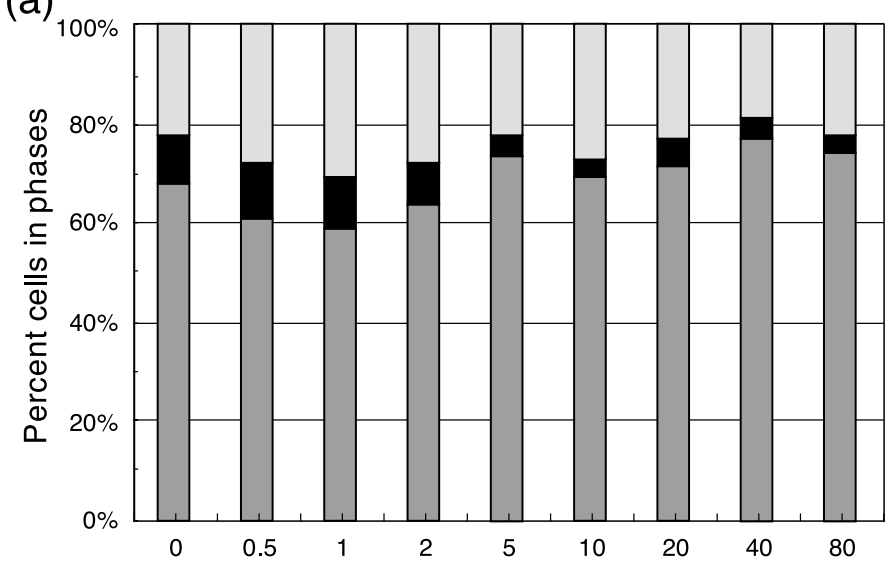

G2/M phases

(b)

Lovastatin $(\mu \mathrm{M})$
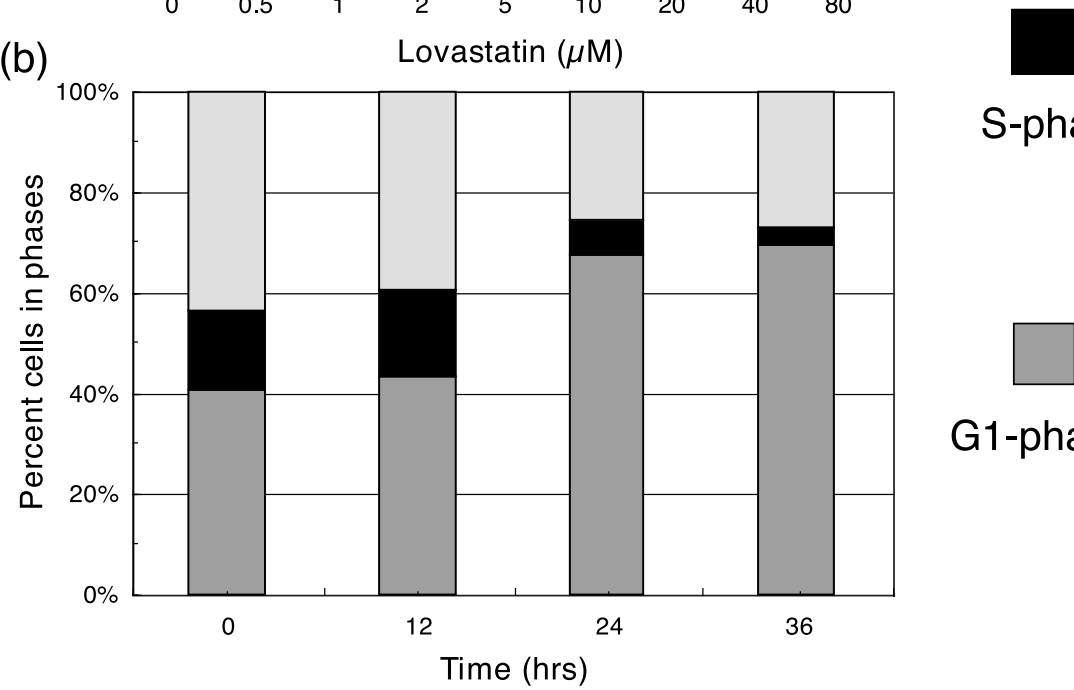

S-phase

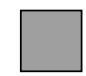

G1-phase

Fig. 6. Published DNA patterns following lovastatin inhibition. In panel (a) published data on the phenomenon of lovastatin inhibition on DNA phases is presented in a graphical form. In the original paper (Rao et al., 1999) the actual results were presented in a tabular form, and those results are now replotted. In panel (b) a time-course of lovastatin inhibition is plotted. In the original paper (Rao et al., 1998) the results were summarized numerically adjacent to flow-cytometry figures. Here those numerical results are plotted as a percent of total phases as a function of time of incubation. The cells used were $76 \mathrm{~N}$ cells transformed by the human papilloma virus E6 (76N-E6). As described in the text of this paper, the cells were treated with $40 \mu \mathrm{M}$ lovastatin for $50 \mathrm{~h}$ and the DNA was analysed at intervals.

Such treatment results in a G1 arrest of 76N-E6 cells despite the absence of p53. [Italics added for emphasis.]

As can be seen from the plot (data originally presented numerically) in Figure 6(b), there is more than G1-phase arrest as there are both G1-phase cells and G2/M-phase cells accumulating at the end of the inhibition period. This is a confirmation of the results reported in the experimental section.

In another study of lovastatin by Jakobisiak et al. (1991), it was reported that, while some cells were arrested with a G1-phase amount of DNA, there were a significant number of cells with a G2-phase amount of DNA. For example, treating the human bladder carcinoma T24 cells with $10 \mu \mathrm{M}$ lovastatin for $24 \mathrm{~h}$ led to growth arrest with an increase in cells with a G1-phase DNA content to $77 \%$ of the population from a control value of $43 \%$. The cells with a G2 amount of DNA remained constant at $\sim 15 \%$. Furthermore a large amount of toxicity was observed; treatment of cells with $50 \mu \mathrm{M}$ lovastatin for $72 \mathrm{~h}$ killed $89 \%$ of the cells. It is possible to conclude that addition of lovastatin to growing cells may cause a slight increase in the fraction of cells with a G1-phase amount of DNA, but it is not clear that a true 'G1-phase arrest' is achieved by lovastatin inhibition.

A recent study of human breast cell lines (Barrett, et al., 2002) showed that treatment of four different cell lines with $20 \mu \mathrm{M}$ lovastatin for $48 \mathrm{~h}$ increased the G1-phase cell fraction from $58 \%$ to 
$78 \%, 52 \%$ to $70 \%, 52 \%$ to $78 \%$, and $56 \%$ to $79 \%$ in the different cell lines. This is difficult to characterize as arrest with a G1-phase amount of DNA. Subsequent DNA analyses of these four cell lines after release from lovastatin treatment did not indicate any synchronization or passage through different phases of the cell cycle in a synchronized manner.

It can be argued that the increase in the percentage of cells with a G1-phase amount of DNA may be interpreted as indicating that 'some cells are arrested in the G1 phase of the cell cycle'. Even if it were true, one should not accept this culture as typical of a synchronized culture. One would never know which cells (the arrested or growing cells) are producing a particular biochemical result. But even more to the point, if cell growth was merely slowed down, with $\mathrm{S}$ and $\mathrm{G} 2$ phases remaining relatively constant, one would have an increase in the fraction of cells with a G1-phase amount of DNA without any arrest of growth (Cooper, 1998a,b).

\section{Experimental analysis of synchronization}

The experiments presented here indicate that a method proposed to synchronize cells by arresting cells with a G1-phase amount of DNA does not appear to result in cells dividing as a cohort over a relatively narrow span of time, our basic criterion for synchronization. In the experiments presented here, there is no indication of any pattern of cell divisions occurring over a relatively narrow span of time indicating synchronization by lovastatin. The pattern analysis (Fig. 3) used here is merely an alternative approach to determining whether cells are dividing as a synchronized cell culture. Although it is more common to present synchrony data in terms of cell numbers as a function of time following a synchronization treatment, the pattern analysis described in Figure 3, and applied in Figure 4, is the precise analogue of such a 'time $v$ s cell number' plot. Because there are relatively few cells in a time-lapse experiment (of the order of 100), the pattern analysis actually gives a clearer indication of cell growth than a standard plot of cell number increase with time.

As with the published G1-phase arrest results discussed above, the same paradox arises as to how to re-examine published experiments demonstrating cell synchronization that were performed in other laboratories and with other cell lines. It is possible that others have actually obtained synchrony but that because of the cell line studied in this laboratory, the methods used (inhibition times, inhibitor concentrations, etc.), or for other unknown reasons, the experiments presented here are unable to reproduce synchronization. However, re-examining the data on synchronization by lovastatin leads to another conclusion.

The original data points of Keyomarsi et al. (1991) suggesting that lovastatin can synchronize cells are plotted in Figure 7(a). These points represent thymidine incorporation rates at various times after 'synchronization'. A peak in thymidine incorporation is taken as indicating an $\mathrm{S}$ phase, and a valley in the tritiated thymidine counts is taken to represent the combined $\mathrm{G} 2 / \mathrm{M}$ and $\mathrm{G} 1$ phases. No cell counts are reported. If one did not know this was a synchrony experiment, it is not clear that one would ascribe 'peaks' to the points in Figure 7(a). In Figure 7(b) the original presentation is drawn with lines connecting the experimental points. The peaks and valleys in Figure 7(b) are proposed to indicate synchronization by lovastatin treatment.

A re-evaluation of the data in Figure 7(a) is presented in Figure 7(c). The curve-fitting program of Microsoft Excel was used to prepare a 'best fit' line to the data; this line is the best fit with a 6th order polynomial function. It appears that the fitting function does not find synchronized peaks in the data. While better fitting functions might be found that support the evidence for synchronized periods of DNA synthesis, one can be skeptical of the original conclusion from the data in Figure 7(a). In Figure 7(d), a dashed line is added to show what would be expected for a change in cell number if the cells were synchronized, assuming the points reflected peaks of DNA synthesis. Cell division would be confined to the valley regions in the graph. The sharp rises required in this case should, if the cells were synchronized, allow one to delineate synchronous divisions. Thus one may be skeptical of this experiment (Fig. 7) as a proof of synchronization.

An interesting support of this conclusion comes from studies on the recovery of T24 cells from lovastatin inhibition (Jakobisiak et al., 1991). Cells arrested with a G1-phase amount of DNA were able to enter $\mathrm{S}$ phase after removal of lovastatin. The earliest entry of cells into $S$ phase was $6 \mathrm{~h}$ after lovastatin removal, while the entrance of the cells into S phase was quite 'asynchronous', as Jakobisiak et al., (1991) described. Thus, S-phase cell number peaked $20 \mathrm{~h}$ after removal of lovastatin, and no second round of cell division was observed. One can only remain skeptical of the claim that lovastatin synchronizes cells.

Out of fairness to the original work proposing lovastatin as a synchronizing agent (Keyomarsi et al., 1991) it should be noted that their Figure 1 

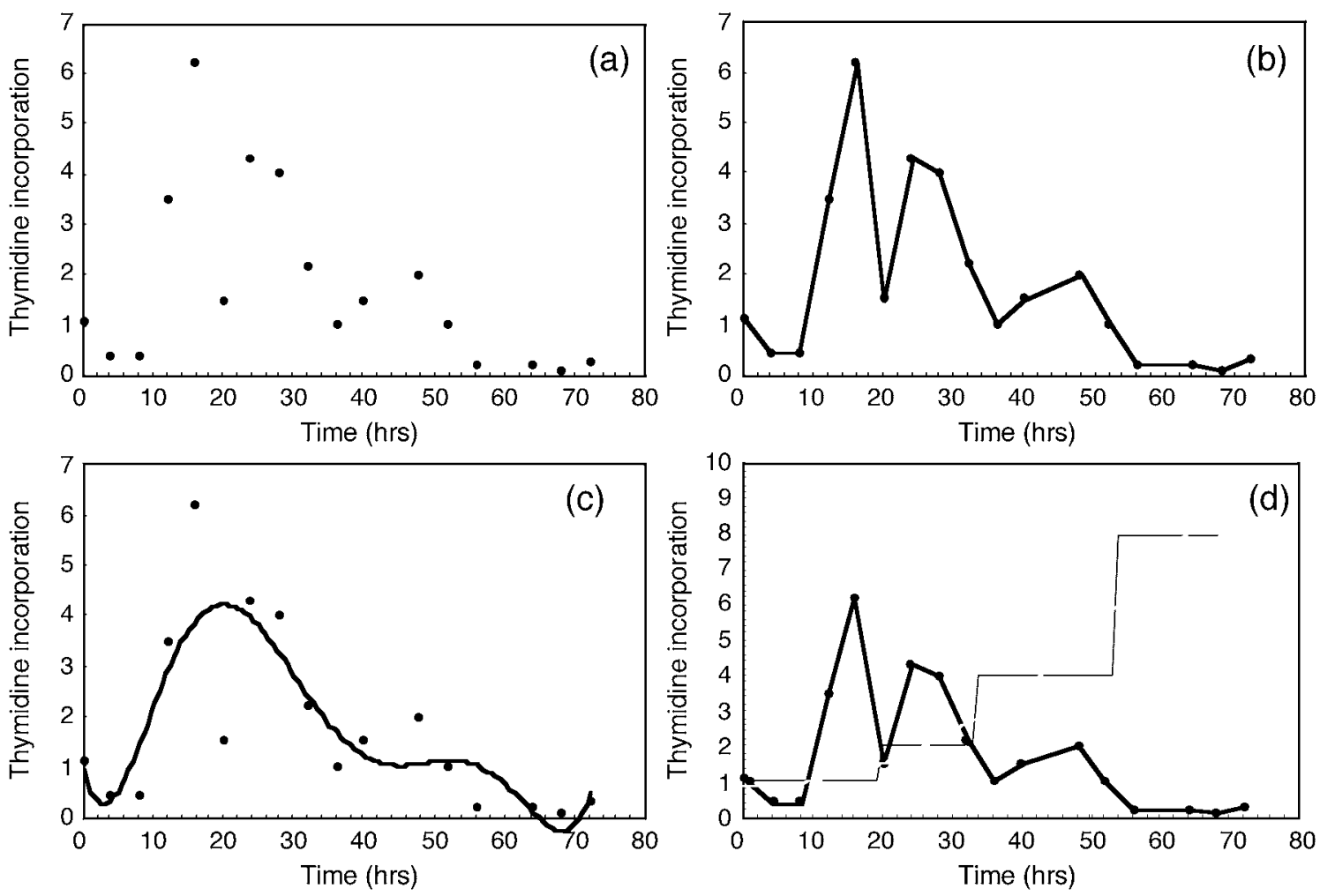

Fig. 7. Analysis of original lovastatin synchronization data. In panel (a) the original points (their Fig. 2) proposing that lovastatin synchronizes cells (Keyomarsi et al., 1991) are plotted. In panel (b) the points are connected as in the original publication. As drawn, three successive peaks of thymidine incorporation are proposed to exist. Between the proposed S phases as indicated by the thymidine incorporation are presumed cell divisions and combined G2/M and G1 phases. In panel (c) the best fit to the data drawn by the polynomial fitting of the Microsoft Excel program is shown (a 6th order polynomial fit was used). In panel (d) the expected cell division pattern (dashed line) expected from accepting that the peaks in incorporation are related to an actual synchronization. Thus, between S-phases division must occur, and the time allowed for division to take placed is determined by the time between $\mathrm{S}$ phases.

showed another experiment on MCF-7 cells where thymidine pulse-labeling indicates three peaks of incorporation. This experiment $(20 \mu \mathrm{M}$ lovastatin for $33 \mathrm{~h}$ ) was reported to have been performed in duplicate and repeated four times. It is not clear whether this experiment is merely one experiment of the eight experiments performed, or whether all of the results are averaged since no error bars are shown. While it is possible to ascribe these results to synchronization, alternative explanations are possible. For example, it is possible that upon release from lovastatin inhibition, three populations of cells are produced, each one proceeding through one cycle of DNA synthesis. The cycles may be of short, intermediate, and long interdivision times. This hypothetical heterogeneous population could give peaks in incorporation, but are not consistent with the whole population being synchronized. The fact that lovastatin can kill cells suggests that this interpretation is not impossible. Unless cell division patterns are correlated with the
DNA incorporation curves, it is not safe to assume that lovastatin has produced synchronized cells merely by looking at thymidine incorporation.

\section{The question of cell strains and reconciling discordant results}

One important question remains: can these studies with one cell line be applied to results obtained with another cell line? Is it possible that synchrony was obtained with other cell lines, and for unknown and various reasons, the lovastatin method for synchronizing cells does not work with L1210 cells? The lovastatin method, when first proposed, was seen as a general method that would work on a number of cell lines, and therefore could be adopted as a relatively universal synchronizing method. It would appear that this is highly unlikely because I have shown that the lovastatin inhibition method does not even appear to synchronize cells in the original publications. Most important, the 
results reported here are consistent with theoretical analyses of arrest/release synchronization (Cooper, 1997, 1998a, 2000).

\section{On the synchronous cell division criterion}

It may be possible to take issue with the celldivision-synchrony criterion used here as a measure of successful cell synchronization. Some have proposed that synchrony decays very rapidly (for example, consider the transition-probability model (Smith and Martin, 1973) and therefore would it be better to look at an earlier event such as 'exit from G1' or the initiation of S phase? I agree that it is widely believed that eukaryotic cells have such a variable cell division cycle that it is not expected that cell division synchrony be maintained. But the recent development of a eukaryotic 'baby machine' (Thornton et al., 2002) where three clear synchronized divisions are observed in a synchronized culture indicates that this argument is invalid. The lack of clear synchronized cell divisions after lovastatin arrest and release is more an indication that the cells are not synchronized rather than that the cells are synchronized but synchrony decays extremely rapidly.

\section{The continuum model}

The results here were foreshadowed in a proposal made over two decades ago (Cooper, 1979). At that time, it was proposed that there are no G1-specific events and that the G1 phase existed when the interdivision time or mass doubling time of a mammalian cell was greater than the sum of the $\mathrm{S}+\mathrm{G} 2+\mathrm{M}$ phases of the division cycle (Cooper, 1991, 1998b). The G1 phase was proposed to be the time when biosynthetic processes begun at the previous $\mathrm{S}$ phase are completed. Since that initial proposal 20 years ago, this viewpoint-since codified as the continuum model - has been applied to a large number of experimental observations (Cooper, 1991, 1998c, 2000, 2001; Cooper and Shayman, 2001, Sheddon and Cooper, 2002 see www.umich.edu/ cooper).

\section{Implications for future use of forced synchronization}

Researchers are well aware of the obvious problems with starvation or inhibition synchronization methods. The possibility that starvation/ inhibition methods may introduce artifacts, that these methods are prone to work only for one division cycle before the synchrony decays, and that the methods are not reproducible, are well known. What is rarely considered is the proposal that such methods may not, as proposed here, synchronize cells at all (Cooper, 1997, 1998a, 2000). Here an experimental support of these theoretical proposals is presented demonstrating that while cells may alter their DNA content pattern (arrest 'in G1 phase'?), unless cell counts are determined following release from starvation or inhibition, it is not clear that such cells are truly synchronized.

\section{ACKNOWLEDGEMENTS}

Dr Eric Sheldon of the Department of Cell and Developmental Biology was invaluable for his modification of NIH Image program to allow rapid cell division analysis. Drs Joel Swanson (of Microbiology and Immunology) and Michael Welsh (Cell and Developmental Biology) were kind in allowing me to use their time-lapse microscopic equipment in order to have two time-lapse experiments going simultaneously. Dr James Shayman was a kind host in allowing me to use his laboratory and cell culture facilities. Dr Charles Helmstetter was helpful with his comments and ideas. The University of Michigan Hospital Flow Cytometry Laboratory helped with the determinations of the DNA contents of cells. This work has been supported by a seed money grant from the University of Michigan Cancer Committee.

\section{REFERENCES}

Abbo FE, Pardee AB, 1960. Synthesis of macromolecules in synchronously dividing bacteria. Biochim Biophys Acta 39: 478-485.

Barrett KLB, Demiranda D, Katula KS, 2002. Cyclin B1 promoter activity and functional CDK1 complex formation in G1 phase of human breast cancer cells. Cell Biol Int 26: $19-28$.

Cho RJ, Huang M, Dong H, Steinmetz L, Sapinoso L, Hampton G, Elledge SJ, Davis RW, Lockhart DJ, CAMPBell MJ, 2001. Transcriptional regulation and function during the human cell cycle. Nat Genet 27: 48-54.

CoOPER S, 1979. A unifying model for the G1 period in prokaryotes and eukaryotes. Nature 280: 17-19.

CoOper S, 1991. Bacterial Growth and Division. San Diego, Academic Press.

COOPER S, 1997. G1 and S phase gene expression cannot be analyzed in mammalian cells synchronized by inhibition. Microbial and Comparative Genomics 2: 269-273.

COOPER S, 1998a. Mammalian cells are not synchronized in G1-phase by starvation or inhibition: considerations of the 
fundamental concept of G1-phase synchronization. Cell Proliferation 31: 9-16.

COOPER S, 1998b. On the interpretation of the shortening of the G1-phase by overexpression of cyclins in mammalian cells. Experimental Cell Research 238: 110-115.

CoOper S, 1998c. On the proposal of a G0 phase and the restriction point. FASEB Journal 12: 367-373.

CoOper S, 2000. The Continuum Model and G1-Control of the Mammalian Division Cycle. Progress in Cell Cycle Research 4: 27-39.

COOPER S, 2001. Revisiting the relationship of the Mammalian G1 phase to cell differentiation. J Theor Biol 208: 399402.

Cooper S, Shayman JA, 2001. Revisiting Retinoblastoma protein phosphorylation during the mammalian cell cycle. Cellular and Molecular Life Sciences 58: 580-595.

Jakobisiak M, Bruno S, Skierski JS, Darzynkiewicz Z, 1991. Cell cycle-specific effects of lovastatin. Proc Natl Acad Sci USA 88: 3628-3632.

Keyomarsi K, Sandoval L, Band V, Pardee AB, 1991. Synchronization of tumor and normal cells from G1 to multiple cell cycles by lovastatin. Cancer Research 51: 3602 3609.

Rao S, Lowe M, Herliczek TW, Keyomarsi K 1998. Lovastatin mediated G1 arrest in normal and tumor breast cells is through inhibition of CDK2 activity and redistribution of p21 and p27, independent of p53. Oncogene 17: 2393-2402.

Rao S, Porter DC, Chen X, Herliczek T, Lowe M, Keyomarsi K, 1999. Lovastatin-mediated G1 arrest is through inhibition of the proteasome, independent of hydroxymethyl glutaryl-CoA reductase. Proc Natl Acad Sci USA 96: 7797-7802.

SHEDDEN K, COOPER S, 2002. Analysis of cell-cycle-specific gene expression in human cells as determined by microarrays and double-thymidine block synchronization. Proc Natl Acad Sci USA 99: 4379-4384.

Smith J, Martin L, 1973. Do cells cycle? Proc Natl Acad Sci USA 70: $1263-1267$.

Thornton M, Eward KL, Helmstetter CE, 2002. Production of minimally disturbed synchronous cultures of hematopoietic cells. Biotechniques 32: 1098-1105. 